\title{
Implementation of Adaptive Neuro Fuzzy Inference System for Malaria Diagnosis (Case Study: Kwesimintsim Polyclinic)
}

\author{
Richard Appiah \\ Department of Computer \\ Science \\ Kwame Nkrumah University of \\ Science \& Technology \\ (KNUST), Kumasi, Ghana
}

\author{
Joseph Kobina Panford \\ Department of Computer \\ Science \\ KNUST, Kumasi, Ghana
}

\author{
Kwabena Riverson \\ Department of Computer \\ Science \\ KNUST
}

\begin{abstract}
Health issues have become one of the problems bedeviling most developing and under-developed countries in our world today. Ghana is of no exception from this menace especially in Africa. One of the prevalent diseases battling with Ghanaians and Africa as a whole is the malaria disease. In 1994, the WHO reported that malaria and measles were the most common causes of premature death. in children under five(5) years. Diagnosis of malaria in many cases has not been accurate by most doctors or physicians due to external human factors such as fatigue and hastiness among others, thereby leading to patients being subjected to treatment again which also come with cost. This paper employs the use of Adaptive Neuro-Fuzzy Inference System (ANFIS) to provide a better option for malaria diagnosis than the traditional diagnosis method which is characterized by erotic guess work and observation of patients by doctors. Datasets of patients divided into training and checking data were used to train the ANFIS. The results tested after training showed that ANFIS has the ability to diagnose malaria efficiently than the traditional method with very minimal error.
\end{abstract}

\section{Keywords}

ANFIS, Malaria, Diagnosis, MATLAB

\section{INTRODUCTION}

Health is defined in the World Health Organization's Constitution as [1] "a state of complete physical, social and mental well-being, and not merely the absence of disease or infirmity". Health can be said to be the driving force for any nation's development. A strong and developed nation is directly related to the strong and healthy mind of its citizens. Therefore health issues are of paramount interest in almost all nations of the world. Most developing and under-developed nations have a huge section of its people suffering from various kinds of ailment. Ghana is of no exception to this rampant spread of sickness and diseases in Africa thereby making a negative impact on the nation's development. Due to this there have been many attempts by nations including Ghana to curb the problems of health related to its citizens. However the introduction of technology into the health sector of many African countries have been less or negligibly exploited. As a result, less number of people can be attended to by physicians on a daily basis. Technology like health management system which is mostly used in the developed countries has been reported to have an immense positive impact on its citizens thereby leading to the nation's development. This system used in the health sector helps in achieving more results that would not have been attained without it. It is obvious that those clinics and hospitals that go the traditional method record less number of people daily when it comes to treatment of diseases. Diagnosing patients and offering them treatment is very important and crucial to the human being. Any interference in diagnosing a patient such as stress, forgetfulness and fatigue can be very dangerous to the patients. Therefore it is expedient that an easier, less brain work, accurate and flexible system be built to help physicians diagnose patients with less effort. This also can deal with the problem of having to attend to limited number of sick people all the time. ANFIS which is a branch of Artificial Intelligence (AI) can play a vital role in medical diagnosis to curb the inaccuracies due to external human factors. ANFIS, which is derived from the term Adaptive Network Fuzzy Inference System, was first proposed by Jang in 1993, [2], and later changed to Adaptive Neural Fuzzy Inference System. This system is designed to allow IF-THEN rules and membership functions (fuzzy logic) to be constructed based on the historical data and also include the adaptive nature for automatic tuning of the membership functions [3]. ANFIS refers to an inference system that integrates the best features of neural network and fuzzy logic. It is a system that predicts input/output relationship of given set of data [4]. It is an adaptive network which comprises of directional links and network of nodes. In association with this network is a learning rule, for example back propagation algorithm. For the reason that some or all of the nodes have parameters which affect the output of the node, it is called adaptive network. In this adaptive network, the adjustment allows the fuzzy systems to learn from the data they are modeling. The operation of the adaptive network is like both Adaptive Neural Network(ANN) and fuzzy logic(FL) whereby the input passes through the input layer by membership functions and the output passes through the output layer by membership functions. Neural network makes use of a learning algorithm in this adaptive network. Thus the parameters are changed until they reach the optimal solution. The FL in this ANFIS tries to use the neural network's advantages to adjust the parameters. Performance can be accessed by establishing the difference the real and network output in ANN. Thus the ANFIS uses either back propagation or combination of least squares estimation and back propagation for membership function parameter estimation [5].

\section{PROBLEM STATEMENT}

Automating procedures tasks have a greater positive impact on any system that is used by any institution, organization or individuals. Automating tasks stand the chance of making tasks easy to accomplish and able to do more than one would naturally do without the automation system. 
However many hospitals and clinics including Kwesimintsim Polyclinic in the Shama Ahanta East Metropolitan Assembly have not exploited the use of I.T and technology to automate most of their activities. It causes a limited number of people to be attended to by the physicians since they have to keenly listen to patients, analyze their situation and diagnose them. It is clear that by this fatigue and stress may set in since the physicians employ the use of guess work in diagnosing the patients. Therefore this approach has caused much wrong and/or inaccurate diagnosis by doctors thereby subjecting patients to re-diagnosing again and even sometimes leading to death. Also patients are delayed in the hospital for a very long time in queues which sometimes deteriorate their condition.

\section{RELATED WORK}

An ANFIS is a fuzzy inference system enhanced with learning generalization and adaptive capabilities. This system has been used in divers areas of research for diagnosis, modeling and prediction. [6] employed the use of ANFIS to serve as a model for breast cancer diagnosis. This work presented a knowledge extraction and classification of breast cancer disease using basically a neuro-fuzzy approach for system design which was able to explain human decisions. Also [7] presented ANFIS as a base for classification model for heart disease prediction. The aim of this study was to develop a method of classifying for heart disease degree of patient based characteristic data using adaptive neuro-fuzzy inference system. This paper concluded that ANFIS technique was a reliable technique for helping patients to quickly get diagnosed. The ANFIS model achieved training and average errors which were 0.01 and 0.15 respectively and was embraced with satisfaction. In the paper presented by [8], ANFIS was successfully used in detecting the presence of brain tumors in patients. In this paper the neuro-fuzzy inference system was used for MR brain tumor image classification. The experiment came out with promising results for ANFIS as an image classifier. Sunging et al came out with an ANFIS based artificial intelligence system for lung cancer diagnosis [9]. Also fuzzy rule based expert system was implemented for asthma diagnosis[10]. Ucar et al [11] delved into a study on tuberculosis diagnosis using ANFIS and rough sets.

\section{METHODOLOGY}

\subsection{Data Collection}

The research was done in Kwesimintsim Polyclinic which is one of the most accessed hospitals in Sekondi-Takoradi Metropolis. Observation, literature survey, interview and consultation were used to gather information about patients and various diseases. Also 100 datasets on patients diagnosed from malaria were collected and trained with ANFIS.

\section{IMPLEMENTATION}

\subsection{Modeling with the ANFIS Editor}

1. First dataset that contains desired input/output data pairs of the target system to be modeled were collected. The datasets are now divided into training and checking datasets.

2. The training and checking datasets are saved in excel files.

3. The training and checking datasets are imported individually into Matlab workspace using the command uiimport in the Matlab command area.

4. The command anfisedit was typed in the Matlab command area to display ANFIS editor dialogue box.

5. In the load data section of the ANFIS editor, training and checking data were loaded by selecting appropriate radio buttons and then clicking Load Data. The loaded data is plotted on the plot region.

6. FIS model was generated by clicking on grid partition in the Generate FIS section of the ANFIS editor.

7. FIS model structure was viewed once an initial FIS has been generated or loaded by clicking the Structure button.

8. The FIS model parameter hybrid optimization method: which is a mixture of back propagation and least squares method was chosen in the Train FIS section of the ANFIS editor. The error tolerance and the training epochs number were also chosen in this section.

9. FIS model was trained by clicking the Train now button. This training adjusted the membership function parameters and plotted the training data error plots in the plot region.

10. The Test button in the 'Test FIS' portion of the ANFIS editor was clicked to view generate the testing plot against the training dataset.

Table 1: Portion of the dataset for training in ANFIS

\begin{tabular}{|c|c|c|c|c|}
\hline No & Temperature & BP & Weight & $\begin{array}{c}\text { Level of } \\
\text { Malaria }\end{array}$ \\
\hline AK001 & 28.7 & 72 & 7.1 & 1 \\
\hline AK002 & 36 & 80 & 37 & 1 \\
\hline AK003 & 35.6 & 120 & 85 & 1 \\
\hline AK004 & 36.2 & 160 & 9 & 1 \\
\hline AK005 & 37 & 120 & 9 & 2 \\
\hline AK006 & 38.5 & 127 & 9 & 3 \\
\hline AK007 & 37 & 80 & 30 & 2 \\
\hline AK008 & 36.6 & 90 & 45 & 1 \\
\hline AK009 & 36.4 & 120 & 41 & 1 \\
\hline AK010 & 36.8 & 100 & 29 & 1 \\
\hline AK011 & 38.1 & 130 & 30 & 3 \\
\hline AK012 & 35.5 & 100 & 33 & 1 \\
\hline AK013 & 36 & 90 & 18 & 1 \\
\hline AK014 & 35.5 & 90 & 66 & 1 \\
\hline AK015 & 36.4 & 120 & 64 & 1 \\
\hline AK016 & 36.1 & 108 & 53 & 1 \\
\hline
\end{tabular}


Table 1 displays the snapshot of the portion of dataset used in training the ANFIS. Temperature, BP and Weight were used as input variables whereas Level of Intensity was used as output variable.

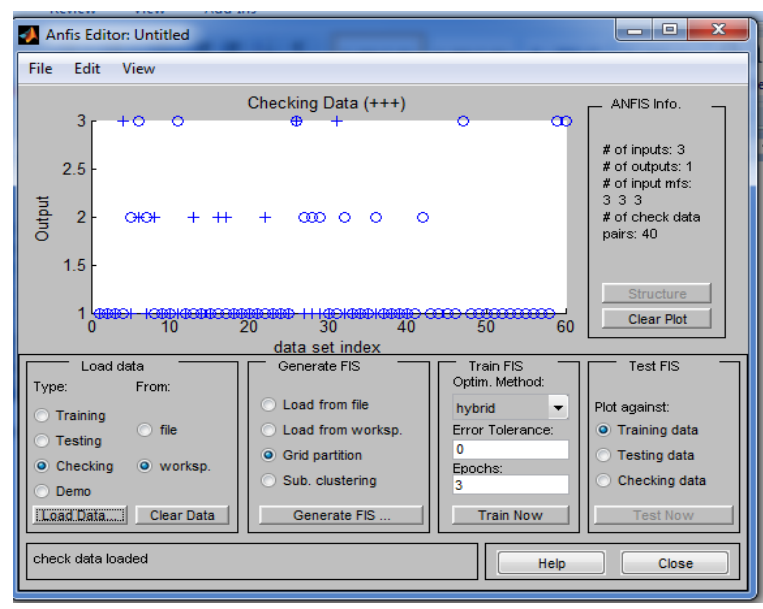

Fig 1: Plot for training dataset

Sixty (60) out of a hundred (100) datasets were selected as training dataset to be loaded into the ANFIS editor. Figure 1 show the plot obtained after loading the training dataset.

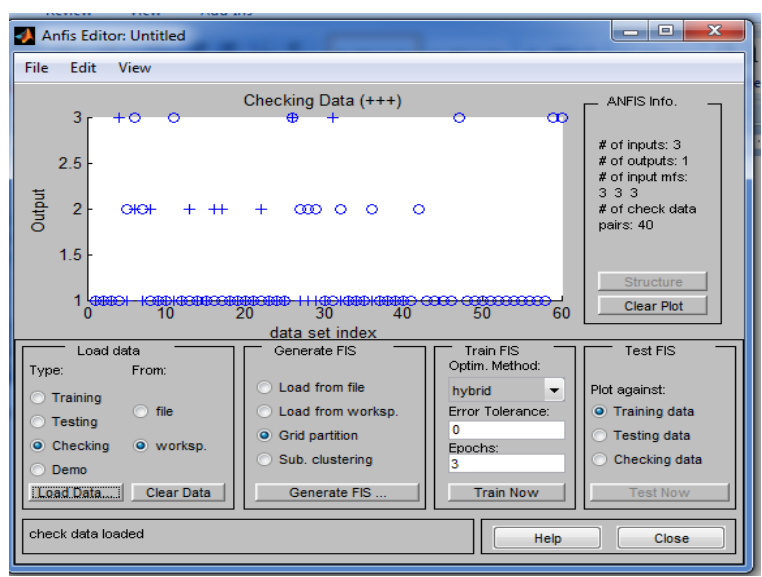

Fig 2: Plot for checking dataset

Also forty (40) out of a hundred (100) datasets were selected as checking dataset to be loaded into the ANFIS editor. Figure 2 shows the plot obtained after loading the checking dataset. The checking datasets are represented by +++ signs.

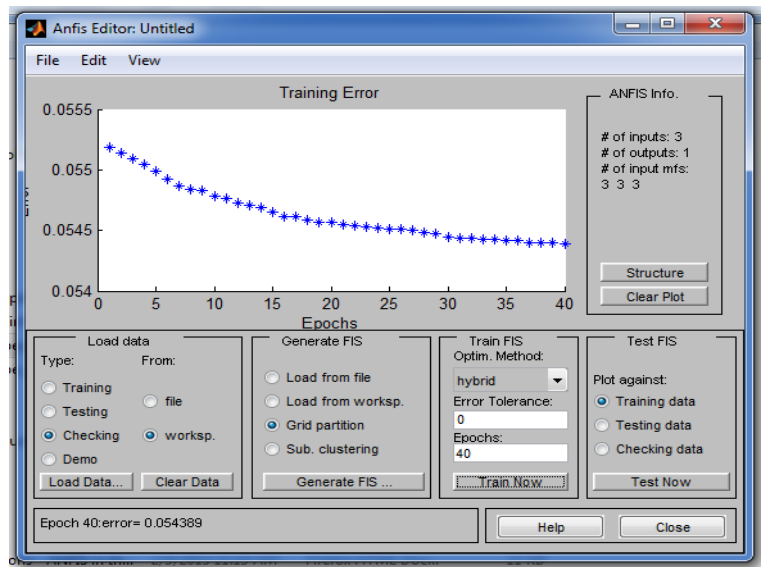

Fig 3: Training the FIS
Figure 3 displays the plot of the trained ANFIS when the button 'Train now' is clicked. The FIS is trained was trained at epochs 40 .

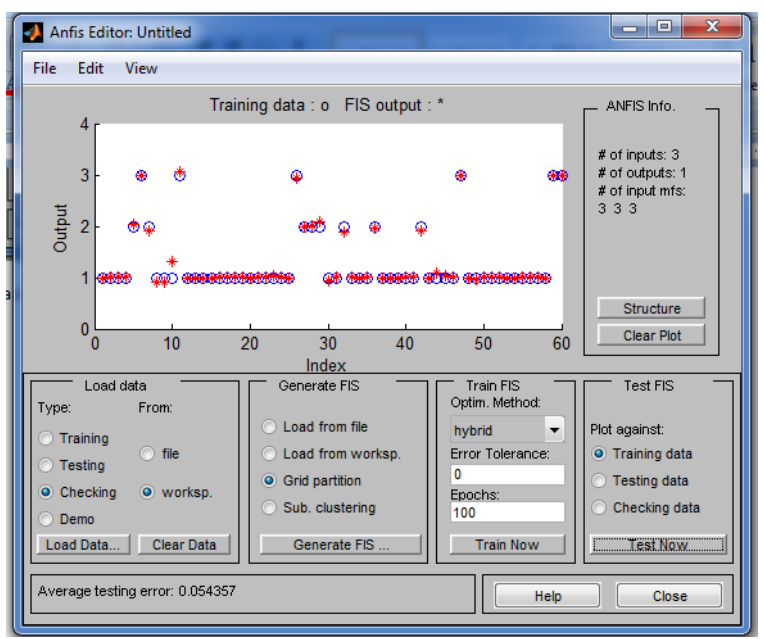

Fig 4: Testing the FIS

Figure 4 shows the plot when the 'Test FIS' button is clicked. At this level the FIS is tested against the training data.

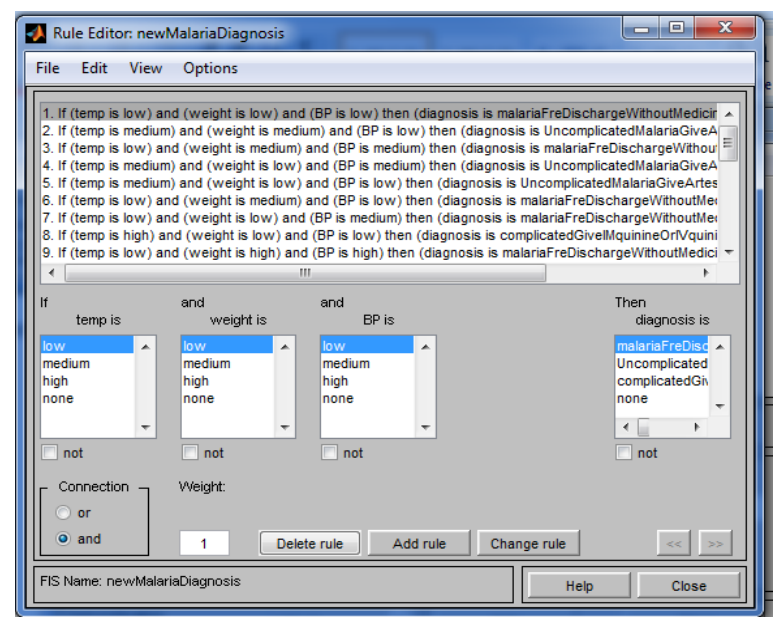

Figure 5: Rule Editor

Figure 5 shows the rule editor of the ANFIS. It displays the input variables with its parameters. Each of the parameters was selected to form a rule as displayed in figure 5 .

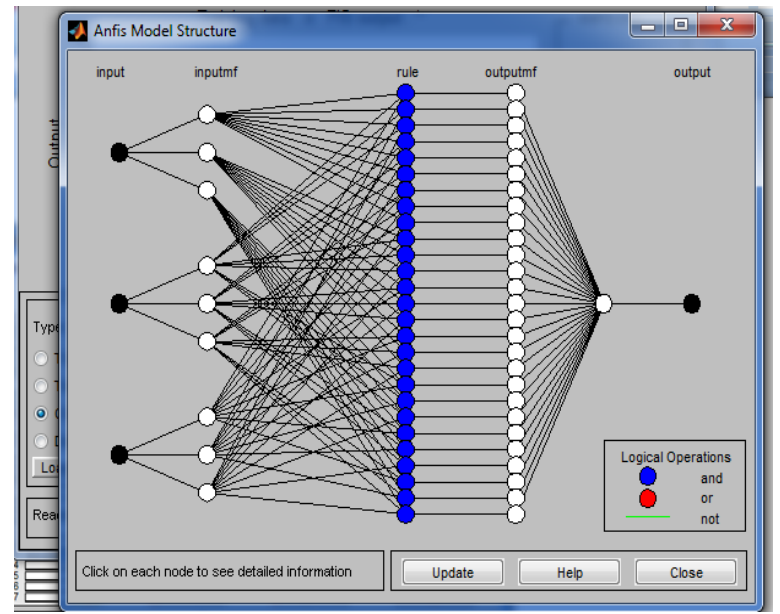

Figure 6: Generated FIS Structure 
Figure 6 shows the generated FIS structure from the ANFIS editor dialogue box. Input parameters were subjected to learning and the result brought out as output.

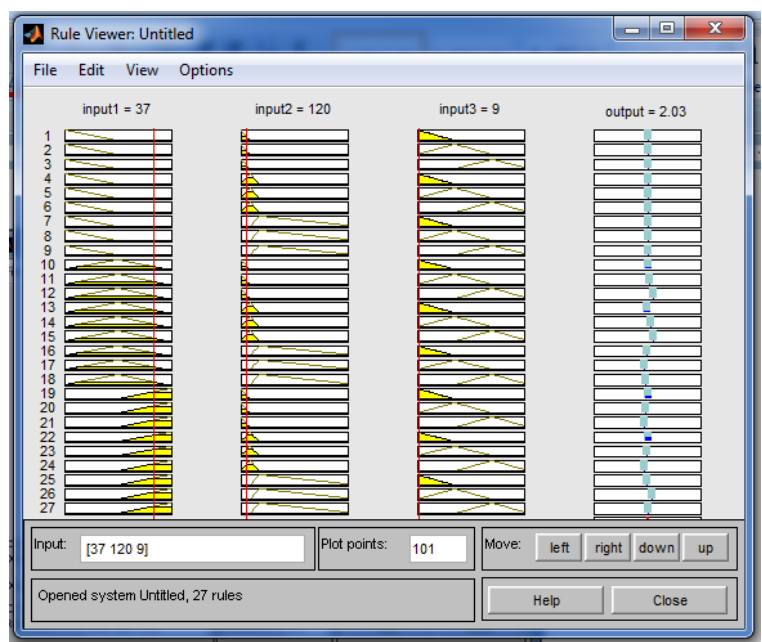

Figure 7: Rule Viewer

Figure 7 displays the rule viewer of the ANFIS. Input values were experimented in the left-bottom box and the result shown in the output column.

\section{COMPARING RESULTS OF THE EXPERIMENTATION}

The purpose of the comparison is to find out how accurate or close the results of ANFIS are close to the expected degree or level of intensity of the malaria condition. Table 2 shows the columns for ID of some selected patients through random picking, expected degree of malaria condition, ANFIS result and ANFIS Diagnosis.

Table 2: Comparison of results of ANFIS and expected Olevel of malaria condition

\begin{tabular}{|c|c|c|c|}
\hline $\begin{array}{c}\text { Patients } \\
\text { ID }\end{array}$ & $\begin{array}{c}\text { Expected } \\
\text { Result }\end{array}$ & ANFIS Result & $\begin{array}{c}\text { ANFIS } \\
\text { Diagnosis }\end{array}$ \\
\hline AK002 & 1 & 1.01 & Malaria Free \\
\hline AK005 & 2 & 2.03 & $\begin{array}{c}\text { Uncomplicated } \\
\text { Malaria }\end{array}$ \\
\hline AK008 & 1 & 0.935 & Malaria Free \\
\hline AK013 & 1 & 0.987 & Malaria Free \\
\hline AK015 & 1 & 0.986 & Malaria Free \\
\hline AK026 & 3 & 2.95 & $\begin{array}{c}\text { Complicated } \\
\text { Malaria }\end{array}$ \\
\hline AK027 & 2 & 2 & $\begin{array}{c}\text { Uncomplicated } \\
\text { Malaria }\end{array}$ \\
\hline AK028 & 2 & 2.01 & $\begin{array}{c}\text { Uncomplicated } \\
\text { Malaria }\end{array}$ \\
\hline AK032 & 2 & 1.89 & $\begin{array}{c}\text { Uncomplicated } \\
\text { Malaria }\end{array}$ \\
\hline AK067 & 1 & 0.964 & Malaria Free \\
\hline
\end{tabular}

\section{DISCUSSION OF RESULTS}

Table 2 shows the ANFIS results of some selected patients. Also given the values for the linguistic input variables, degree or intensity of the malaria condition were assigned to them as output to be modeled in ANFIS. The intensities malaria free, uncomplicated malaria and complicated malaria were coded into figures 1, 2 and 3 respectively. The result after training in table 2 shows very good results. Though there are some differences between the expected malaria intensity and the ANFIS, it can be confidently said that the errors are very minimal. For example the result of patient AK002 after the trained ANFIS is 1.01 which is undoubtedly close to 1. Again patient AK067 had result 0.964 after the trained ANFIS which is also very close to the expected result which is 1 . Patient AK027 had 100\% accuracy in diagnosis since 2 was obtained after ANFIS training equaling the expected result which is 2 .

The researchers realized from the experiment conducted on the sampled patients that their results of level or intensity of malaria condition were very close to the expected degree of malaria condition used as output to train the dataset.

\section{CONCLUSION}

The ANFIS has achieved close results to the expectation of the researchers with very minimal errors. Dataset on patients were collected and divided into training dataset and checking dataset. Sixty percent $(60 \%)$ of the dataset were used for training and forty percent $(40 \%)$ were used for checking. The dataset comprises of patients data on temperature, BP (systolic), weight and the output which represents the level of severity of the malaria disease. The result of the ANFIS approach is seen to be successful following the positive results of such models in other fields of study. However an advance and complex model with several input variables is needed to diagnose several diseases at a time once the symptoms are known. The use of ANFIS in the design of the diagnostic system proposed in this paper is believed to serve as a dependable and cheap means of diagnosing malaria. Furthermore, implementation of ANFIS based medical diagnostic system will reduce doctors' job during consultation and the problem of patients delay in hospitals due to the slowness of the traditional method for diagnosis.

\section{RECOMMENDATION}

Hospitals and clinics in Ghana should employ the use of technology and artificial intelligence such as ANFIS in diagnosing patients to reduce the many guess work done by some doctors which often lead to wrong and inaccurate diagnosis.. It is also recommended that hospitals to invest in enough storage media to safely keep the data of its patients.

\section{SUGGESTED FUTURE WORK}

The ANFIS has proven to be a good tool for modeling systems. Nevertheless, more advanced ANFIS should be designed to be able to diagnose not just a particular sickness in the case of this paper. Also future research in this area should look at some of the safest ways of storing patients' data as this is necessary for use as medical history.

\section{REFERENCES}

[1] World Health Organization 1948. Official Records of World Health Organizatiom. No 2 p 100 http://www.pnf.org/Definition_of_Health_C.pdf. Date Accessed 25/01/2015.

[2] Jyh-Shing R. J., 1993. ANFIS : Adaptive-network-based fuzzy inference system, IEEE Transactions on systems, man, and cybernetics, vol. 23 No.3, pp. 665-685, 
[3] Jang J.S., Sun C.T., Mizutani E. 1997. Neuro-Fuzzy and Soft Computing A computational approach to learning and machine intelligence. Prentice-Hall, Inc., Upper Saddle River, New Jersey,

[4] Piero P. B. 2000. Adaptive neural fuzzy inference systems (ANFIS): Analysis and applications." Lecture notes.

[5] Jang, J.S.R., Sun, C.T. and Mizutani, E 1997. NeuroFuzzy and Soft Computing: A Computational Approach to Learning and Machine Intelligence. First Edition, Prentice Hall.

[6] Bekaddour F and Chikh M. A Neuro-Fuzzy Inference Model For Breast Cancer Recognition. International Journal of Computer Science \& Information Technology (IJCSIT) Vol 4, No 5

[7] Ziasabounchi N. and Askerzade I. 2014. ANFIS Based Classification Model for Heart Disease Prediction.
Intenational Journal of Electrical and Computer Sciences. IJECS-Ijens. Vol 14 no:02.

[8] Sharma M and Mukharjee S. 2012. Artificial Neural Network Fuzzy Inference System(ANFIS) for brain tumor detection.

[9] Sungging, H.W., Sylvia Ayu, P., Santoso, M.Y., Arifin, S., 2011. Application of Adaptive Neuro Fuzzy Inference System (ANFIS) for Lung Cancer Detection Software, Nominator TICA Cluster II.

[10] Zarandi, M.H.F, Zolnoori, M. M., Heidarnejad, H., 2010. A fuzzy-rule based expert system for diagnosing asthma, Transaction E: Industrial Engineering, 17(2), pp. 129142.

[11] Ucar, T., Karahoca, A, Karahoca, D., 2012. Tuberculosis disease diagnosis by using adaptive neuro fuzzy inference system and rough sets, Neural Comput\&Applic. 